\title{
¿UNA NUEVA DEMOCRACIA PARA EL SIGLO XXI?
}

UMA NOVA DEMOCRACIA PARA O SÉCULO 21?

A NEW DEMOCRACY FOR THE 21ST CENTURY?

JoAn Subirats ${ }^{1}$

$\mathrm{P}$

robablemente, no hay término más discutido y debatido en la historia de las ideas políticas que el de democracia. Con esta afirmación da inicio un ambicioso libro que han coordinado Quim Brugué, Simone Martins y Carmen Pineda Nebot. Un libro publicado en formato electrónico por CLACSO (disponible en: https://www.clacso.org.ar/libreria-latinoamericana/inicio.php) y que puede descargarse libremente en su web. El libro lleva por título ¿Una nueva democracia para el siglo XXI?, y ha congregado en sus veinte capítulos a más de treinta autores brasileños y españoles.

El volumen es el resultado del trabajo de uno de los grupos de trabajo que CLACSO incorporó en su convocatoria del trienio 2016-2019. Concretamente del Grupo de Investigación sobre Espacios Deliberativos y Gobernanza Pública (GEGOP). Una muestra más de lo importante que es una plataforma de reflexión y trabajo conjunto en ciencias sociales entre académicos de países muy distintos en trayectoria histórica, en escalas de desarrollo y en contextos y coyunturas concretas. Compartimos lenguas, compartimos espacios de conocimiento y, sobre todo, voluntad de conectar investigación y reflexión con dinámicas de transformación social.

En un libro muy reciente, Wolfang Streeck (2020) afirma que hacer una revisión de un libro es una tarea muy importante ya que implica establecer una comunicación entre académicos, entre personas que dedican su tiempo a pensar y reflexionar sobre lo que acontece a su alrededor. Muchas veces, la oportunidad de comentar un libro genera también la posibilidad de decir lo que uno piensa con relación al tema suscitado por el autor o autores, aunque esas reflexiones puedan tener una relación más bien tangencial sobre el contenido del libro. En este caso, mis comentarios tratarán de vincularse con el libro ya mencionado, pero advierto al lector que también aprovecharé este espacio para decir cosas sobre las que los autores de ¿Una nueva democracia para el Siglo XXI? ni han dicho ni sobre las que tienen de estar forzosamente de acuerdo.

Ellibro presenta un buen aparato crítico sobre lo que podríamos denominar los inputs dela democracia: las dinámicas y formatos de representación, la legitimidad de esa representación, las transformaciones que provoca la digitalización en las posibilidades de participación y las distorsiones que también se generan, las respuestas populistas a la crisis de confianza de las democracias, con un análisis más concreto del "trumpismo" en los EEUU. En el resto del volumen se abordan temas más vinculados con la participación ciudadana en sus distintos formatos, analizando procesos de mejora vinculados a la transparencia, la innovación social o dinámicas más conectadas con la democracia directa y la acción colectiva. Hay muchos ejemplos concretos, análisis de casos y experiencias que enriquecen las aportaciones teóricas. El volumen presenta un panorama muy rico por la variedad de países, escalas de gobierno y dinámicas concretas analizadas.

Reseña del libro: BRUGUÉ, Q.; MARTINS, S.; PINEDA, C. (orgs.). ¿Una nueva democracia para el siglo XXI? Buenos Aires: CLACSO, 2020.

1.Universitat Autònoma de Barcelona - Bellaterra, Catalunya, España. E-mail: joan.subirats@uab.es

Editor de Sección: Ivany Pino 
El libro se inicia con una introducción, firmada por los coordinadores del volumen, en la que ya apuntan a los principales elementos que componen este trabajo colectivo. Se parte de una mirada crítica hacia una democracia liberal y representativa, definida como "de mínimos", con una clara componente de desconfianza hacia la potencialidad participativa de la ciudadanía. En la medida que el modelo de Estado del bienestar ha ido siendo menos capaz de cumplir las promesas de progreso y bienestar colectivo que encarnaba, han ido aumentando las críticas y la desconfianza, tanto hacia los inputs del sistema (instituciones, partidos, elecciones...) como hacia los outputs, es decir la capacidad de provisión de servicios, la capacidad mantener lógicas efectivas de protección social.

El volumen se cierra con un capítulo de alguna manera conclusivo, en el que, a partir de la reciente experiencia constituyente chilena, se ponen en cuestión las premisas de fondo de la democracia liberal, entendiendo que muchas veces cuando hablamos de democracia estamos refiriéndonos a un "significante sin significado", muy condicionado por los intereses de un sistema económico para nada respetuoso con los procesos de decisión colectiva. Lo que obligaría a buscar nuevos parámetros que permitan condensar las necesidades de reconocimiento de la diversidad con la salvaguarda ambiental del planeta, y formas de decisión colectiva que combinen formas democráticas representativas, participativas y comunitarias.

No creo que pueda discutirse la situación de erosión y pérdida de legitimidad que el sistema democrático, en sus distintas variantes y especificidades territoriales, ha ido padeciendo en los últimos decenios. El llamado Libro blanco de la gobernanza europea lo reconocía sin ambages hace ya 20 años. ${ }^{1}$ La literatura sobre las sucesivas crisis de la democracia no ha hecho sino crecer en todo este tiempo, proliferando los ensayos que apuntan a que la crisis actual de la democracia es más bien aguda o, incluso, terminal (LEVITSK; ZIBLATT, 2018; DELLA PORTA, 2013; MOUNK, 2018; RUNCIMAN, 2018).

Los nexos de causalidad para determinar cuales son las razones y hechos que explican tal diagnóstico exceden en mucho la modestia y el alcance de esta revisión. Pero, entiendo que no puede atribuirse esta erosión generalizada de credibilidad exclusiva o preferentemente a déficits en la capacidad representativa del sistema o en las evidentes dificultades de incorporar de manera más clara las preferencias ciudadanas en los procesos decisionales. En la medida en que los cambios tecnológicos, los procesos de globalización se extienden y existe una gran incertidumbre sobre el futuro, proliferan las dudas sobre las capacidades protectoras y proveedoras de seguridad de las instituciones públicas. Como se afirma en la ya mencionada introducción al volumen: "la incapacidad del modelo de responder con eficacia a los problemas crecientemente complejos de la sociedad." Es decir, la parte de los outputs del sistema.

Parece claro que las consecuencias políticas que se deriva de esta situación no pueden desdeñarse. Las bases de un cierto equilibrio social, que sin duda es distinto en cada país, tiene componentes de legitimidad derivada de la representatividad y apertura del sistema, pero también de la capacidad de provisión y protección que la institucionalidad política es capaz de generar. Una capacidad que, de alguna manera y con distintos niveles de desarrollo y arraigo, se habían construido en los estados con políticas de bienestar significativas. La globalización y financiarización del sistema ha acentuado la extrañeidad o lejanía de las minorías capaces de drenar el sistema a su favor, sin que se den perspectivas de redistribución y protección suficientes.

Podríamos pues añadir a los abundantes ejemplos que se ofrecen en el volumen aquí comentado de deslegitimidad, mal funcionamiento de la lógica representativa o las notables carencias de las dinámicas participativas de la ciudadanía, la insuficiente capacidad protectora del sistema. Podríamos incluso preguntarnos si la erosión de los valores democráticos de igualdad y representación derivan también de esa mayor dificultad de mantener la capacidad redistributiva y protectora de manera generalizada, por un lado, y, por el otro, la indudable capacidad de las elites financieras para influir en todo tipo de decisiones en cualquier parte del mundo. 
El cambio de época que atravesamos, impulsa, como ya hemos comentado, una gran sensación de riesgo en la escena social, y al mismo tiempo aumentan las dudas sobre la vitalidad y fuerza del sistema democrático para seguir manteniendo su vis protectora y al mismo evitar procesos de cerrazón autoritaria. En esa encrucijada, los hay que apuestan por la necesaria complementariedad entre un capitalismo avanzado tecnológicamente y un sistema democrático que siga garantizando protección, un sólido sistema de derechos y libertades y la promesa de un cierto ascenso social en términos de bienestar para las generaciones futuras (IVERSEN; SOSKICE, 2019, p. 257 et seq.). Mientras que la tendencia a salidas autoritarias y de rechazo a una globalización y cambio tecnológico que se ve invasivo y contrario a las propias raíces, se extiende como una reacción airada contra los "otros", contra las disrupciones que alteran "lo tradicional", o incluso la propia identidad masculina (SAUER, 2020). En definitiva, una incertidumbre que quiere combatirse con lo que se percibe como firmeza autoritaria (KITSCHELT; MCGAAN, 1995; KRIESI; PAPPAS, 2015; BANERJEE; DUFLO, 2020, p. 318 et seq.)

Las coordenadas estructurales que exige la economía del conocimiento y la innovación digital no solo no deberían poner en cuestión el sistema democrático, sino que más bien parecen necesitar los valores y la capacidad de equilibrio social que incorpora para poder desplegar todo su potencial. La dinámica competitiva inherente al capitalismo, y más en momentos de "destrucción creativa" como los actuales, no es capaz de hacer frente los problemas de decisión colectiva que se plantean en sociedades que sean socialmente avanzadas. En la medida en que el avance hacia la sociedad digital necesitará de una gama nada desdeñable de políticas de regulación y acompañamiento, tanto "nacional" como global, esa interrelación entre democracia, representatividad y capacidad protectora sigue siendo especialmente relevante.

Animamos pues a la lectura de este magnífico volumen que reúne una gran cantidad de académicos, de países muy distintos, pero todos implicados en una aproximación a los problemas sociales y políticos basada en el compromiso y la transformación social.

\section{Referencias}

BANERJEE, A.; DUFLO, E. Buena economía para tiempos difíciles. Barcelona: Taurus, 2020.

DELLA PORTA, D. Can democracy be saved? Cambridge: Polity Press, 2013.

IVERSEN, T.; SOSKICE, D. Democracy and prosperity. Reiventing capitalism through a turbulent century. Princeton: Princeton University Press, 2019.

KITSCHELT, H.; MCGAAN, A. The radical right in Western Europe. A comparative analysis. Ann Arbor: University of Michigan Press, 1995.

KRIESI, H.; PAPPAS, T. European populism in the shadow of the Great Recession. Colchester: ECPR Press, 2015.

LEVITSKY, S.; ZIBLATT, D. How democracies die. New York: Crown, 2018.

MOUNK, Y. People vs democracy. Cambridge, MA: Harvard University Press, 2018.

RUNCIMAN, D. How democracies end. London: Profile Books, 2018. 
SAUER, B. Authoritarian right-wing populism as masculinist identity politics. The role of affects. In: DIETZE, G.; ROTH, J. (eds.). Right-wing populism and gender: European perspectives and beyond. Bielefeld: transcript Verlag, 2020. https://doi.org/10.14361/9783839449806-002

STREECK, W. Critical encounters. Democracy, Capitalism, Ideas. London: Verso, 2020.

\section{Notas}

1. Disponible en: https://ec.europa.eu/commission/presscorner/detail/en/DOC_01_1. Acceso en: 30 mayo 2021.

\section{Sobre el Autor}

Joan Subirats es Dr. en Ciencias Económicas por la Universidad de Barcelona, catedrático de Ciencia Política e investigador del Instituto de Gobierno y Políticas Públicas (IGOP) en la Universidad Autónoma de Barcelona, universidad en la que en la actualidad ejerce como Profesor Emérito.

Recibido: 14 jun. 2021

Aceptado: 24 jun. 2021 